Gut, 1968, 9, 232-236

\title{
Computer analysis of intraluminal pressure records
}

\author{
J. J. MisieWiCZ, Sheila L. WAlleR, M. J. R. HeAly, AND E. A. Piper \\ From the M.R.C. Gastroenterology Research Unit, Central Middlesex Hospital, \\ London, the M.R.C. Clinical Research Centre, London, Department of Engineering, \\ and the National Institute for Medical Research, London
}

Although with modern electromanometric and radiotelemetering techniques it has become relatively easy to record accurately intraluminal pressures from the alimentary tract, the analysis of such pressure records remains unsatisfactory, laborious, and unstandardized (Connell, Texter, and Vantrappen, 1965). Visual inspection of the tracing may yield valuable information in many circumstances, but it is necessarily subjective and the results cannot be expressed in mathematical language. Attempts at a morphological classification of the pressure waves into various types distinguished by variations in amplitude and duration of the pressure peaks (Adler, Atkinson, and Ivy, 1941; Posey, Dearing, Sauer, Bargen, and Code, 1948; Posey and Bargen, 1951; Spriggs, Code, Bargen, Curtiss, and Hightower, 1951; Code, Hightower, and Morlock, 1952; Lind, Duthie, Schlegel, and Code, 1961) have not proved generally satisfactory, partly because the recorded characteristics of pressure waves depend to some extent on the type of sensing device used to detect them, but mainly because the activity of alimentary smooth muscle produces a continuous spectrum of variations in amplitude and duration of the pressure peaks, rather than morphologically distinct types. This is especially true in the colon. However, the qualitative differences of amplitude, frequency, and duration remain useful as localizing parameters for pressuresensitive devices within the lumen of the gut (Atkinson, Edwards, Honour, and Rowlands, 1957; Misiewicz, Waller, Fox, Goldsmith, and Hunt, 1968).

Various attempts have been made to devise methods which would allow the results of intraluminal pressure studies to be expressed in numerical terms. Thus the area under the pressure curve can be estimated by planimetry (Chapman, Rowlands, Taylor, and Jones, 1950; Logan and Connell, 1966) or calculated from the weight of the recorder paper included under the pressure tracing (Arfwidsson, 1964). Others have measured the amplitude and duration of each pressure wave and have calculated various arbitrary indices of motility based on these variables and directly related to the total amount of pressure activity occurring in a given observation period (Chaudhary and Truelove, 1961; Connell, 1961; Deller and Wangel, 1965; Vantrappen, Hellemans, and Vandenbroucke, 1965; Misiewicz, Waller, and Eisner, 1966). An advanced form of mathematical analysis of the wave forms has been attempted by Farrar (Small, Brean, and Farrar, 1955; Farrar, 1960).

All of these methods are extremely laborious and time consuming, and simple considerations of time and availability of skilled labour set a very definite limit to the amount of numerical data that can be extracted from a given pressure record. The observer error inherent in previous methods of analysis may be considerable. If, in the light of later knowledge, it is desired to re-analyse previous studies, the whole tedious procedure has to be repeated, a task daunting to all but the most dedicated of investigators. On the other hand, as the functional significance of various types of motor activity is only very imperfectly understood, it would seem wise to provide for the fullest possible analysis by a method which is flexible enough to allow for the data to be examined in many different ways on different occasions.

We have therefore developed the present technique of computer analysis of intraluminal pressure records in order to lessen the expenditure of work and time required for the task of acquiring data and to facilitate multifactorial analysis of the pressure records. As well as using the computer as a calculating machine, the present technique permits the easy storage and rapid retrieval of information from previous studies and enables repeated analyses of previously acquired data to be carried out in new ways.

PRINCIPLE OF METHOD AND CHOICE OF SYSTEM Any curve can be described by a series of numerical $\mathrm{x}$ and $\mathrm{y}$ coordinates. Thus continuous information 


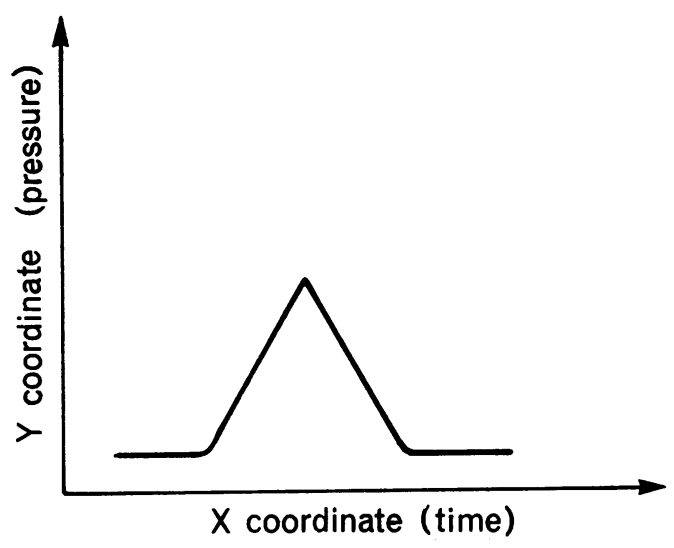

FIG. 1

on the pressure tracing (analogue data) can be converted into a series of numerical $x, y$ coordinates (digital data), the digital information being stored on punched paper tapes. The tapes can be analysed by computer in any way desired, if the computer is instructed by a suitable written program. In the pressure records time has been designated as the horizontal ( $\mathrm{x}$ ) coordinate, and pressure as the vertical (y) coordinate (Fig. 1).

Analogue to digital conversion could be done automatically and simultaneously with the pressure record made during a test on the patient (on-line system). An on-line system, however, requires fast digitizing apparatus and frequent sampling of the record to ensure that no information is lost, thus increasing very considerably the quantity of data to be processed by the computer and the cost of the apparatus. Moreover, artefacts and shifts of baseline produced by respiration, coughing, body movement, and the like are not uncommon in intraluminal pressure records. Automatic recognition of these, either by electronic equipment (hardware) or by programming techniques (software), presents formidable difficulties. Farrar and his colleagues have published an exploratory study of this approach (Farrar, Elfbein, Steinberg, and Bloom, 1964).

It was therefore decided from the start that an off-line digitizing process would be used in which the pressure trace made in the usual way is digitized at some later date, the process of digitization involving a human operator. Apart from considerations of cheapness and simplicity of the off-line system, it was advantageous to make use of the operator's skill as an essential link in the processing of the pressure trace. This was done in two ways. First, the operator scanned each trace and marked in the positions of the baseline and of any pressure artefacts present. This technique was already in use in the manual system of analysis; although subjective, it is nevertheless the only practical method of allowing for shifts in the baseline. While digitizing, the operator reset the y coordinate to zero, wherever a baseline shift occurred. Secondly, rather than recording the trace coordinates digitally at equal intervals of time, the only points recorded were those at which the trace significantly changed direction. This meant that stretches of 'noise' between pressure waves (designated 'events') were skipped over and consequently that the number of points to be digitized was kept reasonably small. Initially the operator was instructed to record a strictly alternating sequence of peaks and troughs within an event, but this proved unduly restrictive. The start and finish of an event were not explicitly marked but were recognized by the program by the occurrence of points on, or very near, the baseline.

In addition to the features discussed above, the off-line system possesses the further advantage of permitting the digitization of previously obtained records.

DESIGN OF THE ANALOGUE-DIGITAL CONVERTER AND PROGRAM PROCEDURE

The analogue digital converter (Fig. 2) comprises a data logger which includes a four-digit digital voltmeter and punch driver (Solartron LM 1420.2 and L.U. 1718), a paper tape punch (Addo LX 1655), and also a chart transport unit with curve-following facilities and appropriate mechanical-electrical transducers.

A standard typewriter carriage was used as the basis for the chart transport unit, thus reducing considerably the amount of mechanical development involved in the construction of the analogue digital converter. The pressure records travel downwards in the typewriter carriage, enabling the operator to see the trend of the pressure curve ahead. For the digitization of data on the time $(x)$ coordinate, the carriage platen is coupled to a ten-turn potentiometer (Beckman Helipot model A, Fig. 2, X). Voltage applied to the potentiometer is so arranged that $1,000 \mathrm{~mm}$ of chart is represented by 10.00 volts. This means that the $\mathrm{x}$ coordinate can be digitized to the nearest millimetre, which is normally equivalent to 2 seconds on the chart. The pressure $(y)$ coordinate of the chart is traversed by a perspex cursor equipped with a graticule. The position of the cursor is altered to follow the curve by adjusting the control knob Y' (Fig. 2), which is coupled to a single turn potentiometer (Beckman model L, Fig. 2, Y). Full-scale deflection of each multichannel recorder pen is $50 \mathrm{~mm}$ and this is represented by 1,000 volts on the potentiometer, so that the $y$ coordinate can be digitized to the nearest half millimetre. Typical pressure changes for full-scale pen deflection lie within the range of 30 to $60 \mathrm{~mm} \mathrm{Hg}$. The two potentiometers are coupled to their driving shafts via friction clutches. This arrangement prevents overtravel, allows for rapid 


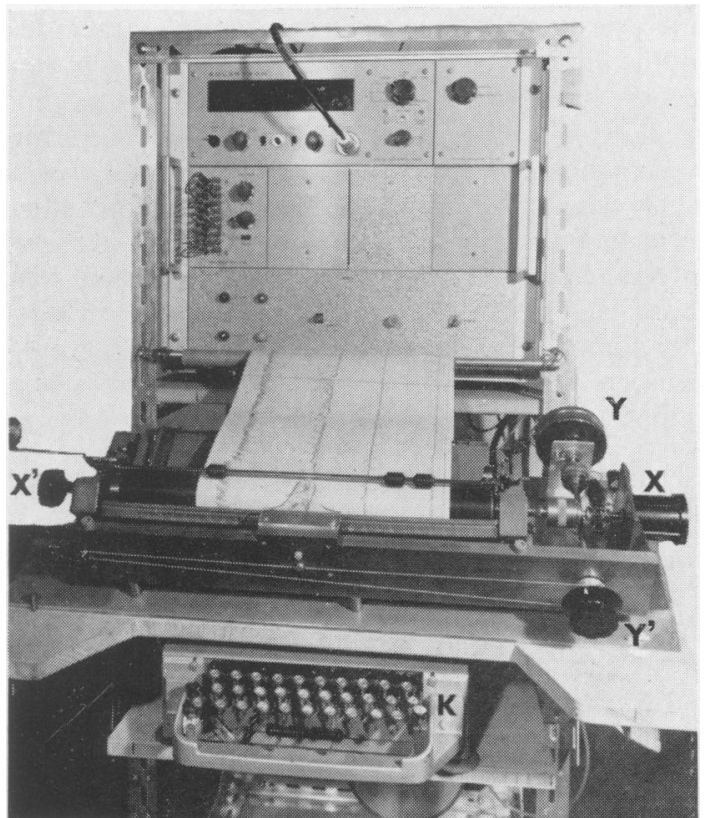

FIG. 2. The analogue to digital converter $X^{\prime}-X$ coordinate control knob and transducer; $Y^{\prime}-Y$ coordinate control knob and transducer. $K$ keyboard. The paper tape punch is placed beneath the digital voltmeter.

adjustment of the baseline to zero and enables easy transition between pressure leads on the same chart.

Additional units were developed to permit the sequential scanning of the $\mathrm{X}$ and $\mathrm{Y}$ potentiometers and the automatic insertion of fixed characters after each numerical coordinate. This allows the printing of the punched tape on a standard tape-editing set for checking purposes. The scanning is carried out automatically for each pair of coordinates and is initiated by the operator pressing a foot switch. A keyboard was provided (Fig. 2, K), so that headings, patients' names, and other notes can be entered on the punched tape along with the coordinate information.

The chart is prepared for digitization by drawing in the baselines and marking any artefacts on the pressure trace. It is then placed in the analogue digital converter and the operator punches the appropriate code and headings using the keyboard. Calibration points for each of the pressure-sensitive devices are then recorded for each pressure lead. At present, three pressure leads can be handled by the program, but the number may be varied to suit individual requirements. The end of each pressure lead is signified by means of an appropriate punched character.

The program for analysing the digitized information was written in Algo for the ICT Atlas computer incorporating a machine-code procedure which reads a single character from the data tape and provides its value in numerically coded form. This was used inside a procedure which reads from the tape a pair of coordinates, at the same time storing for comparison the coordinates of the previous point. This procedure detected the occurrence of non-numeric characters: one such character was used to mark the end of a lead, while others could occur through transient faults in the equipment. It also set an indicator if a point had a y coordinate less than 5, that is, equal to $2.5 \mathrm{~mm}$ on the chart. Such a point was assumed to lie on the baseline and so mark the start or finish of an event. Again, this variable can be altered to suit individual requirements.

The 'readpoint' procedure was itself used inside a procedure which analysed a single lead, providing the number of events, the number of peaks per event, the height of each peak, the duration of each event; the percentage duration of activity; and an index of total activity obtained as the area of the trace above the baseline. This last was calculated by effectively joining the recorded points with straight lines; it is termed 'average intensity' on the printout and corresponds to

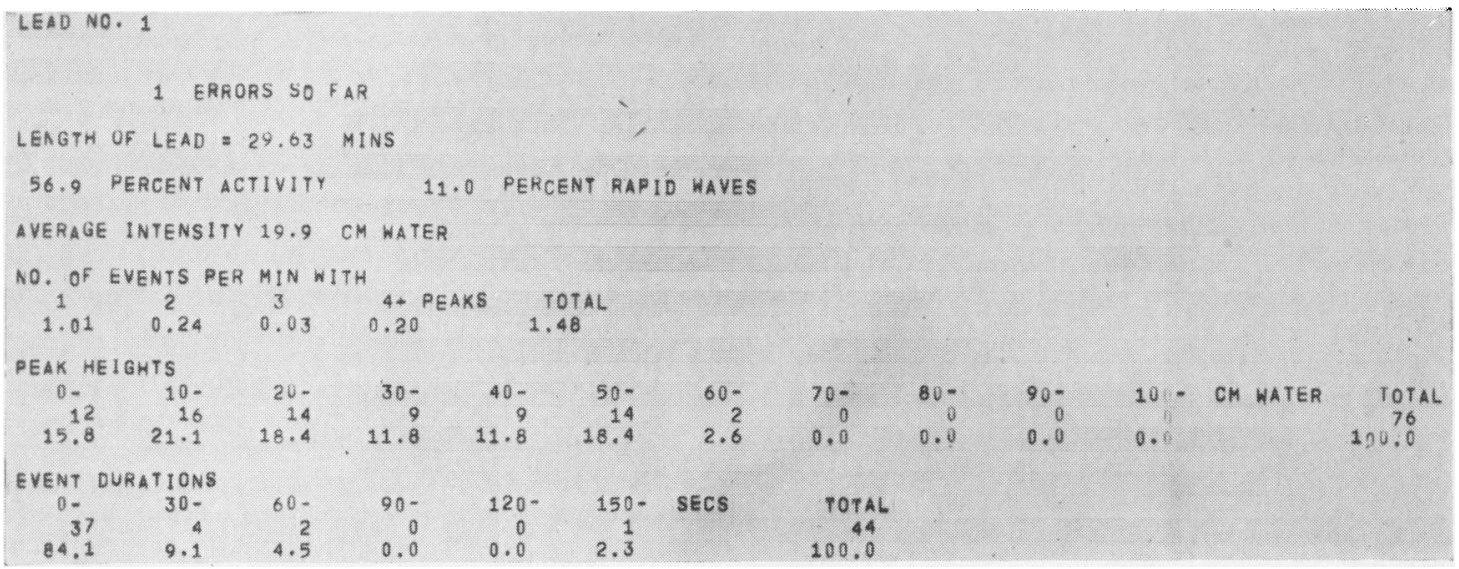

FIG. 3. Computer printout of analysis of one pressure lead. 


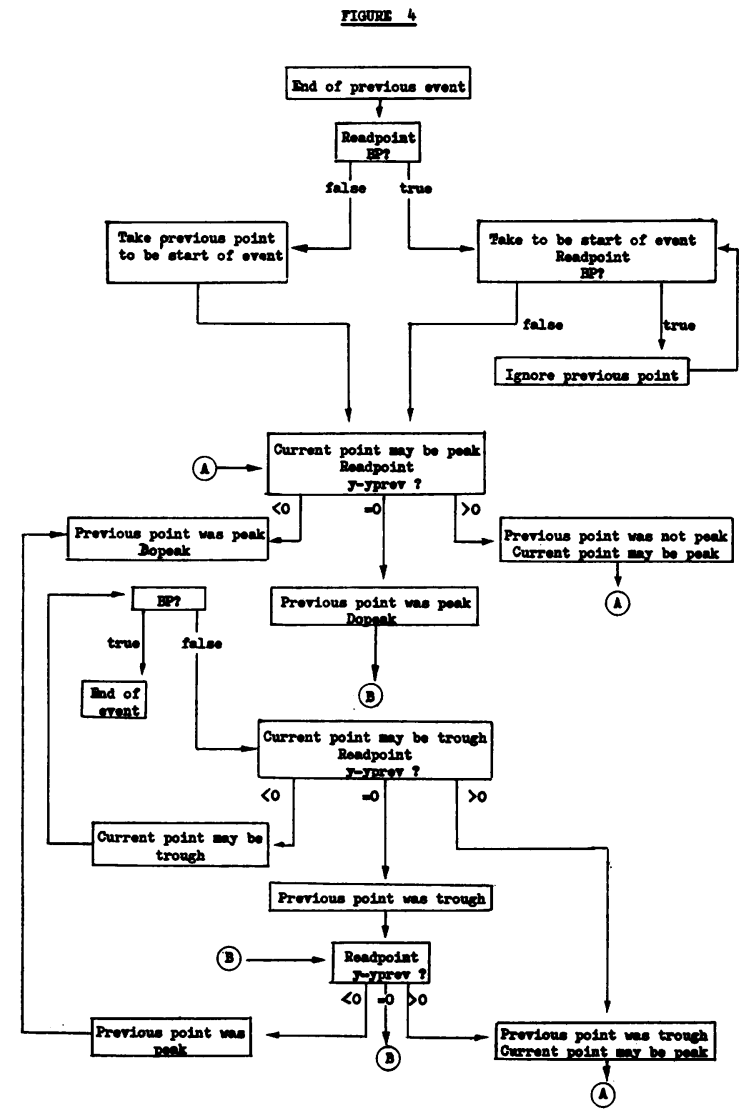

FIG. 4. Flow diagram of program procedure dealing with a single event. Readpoint is a procedure which provides the current ordinate (y) and the previous ordinate (yprev). $B P$ (baseline point) is true if the current point is on the baseline.

Dopeak is a procedure which updates the statistics of the current lead to include data from the latest peak.

the motility index calculated by the manual method (Misiewicz et al., 1966). 'Rapid' events, defined as those with at least three peaks occurring at an average rate of at least 5 peaks/min, were detected and their total duration recorded. At the end of each lead the results, mainly summarized in the form of frequency distribution, were printed out. A specimen of the output for one pressure lead is shown in Figure 3. In addition to the facilities described, the program provided for the input of the calibration data digitized from the traces at the start of each record, and also for the transcription of heading information recorded on the data tape.

The logic of the 'analyse' procedure became fairly complicated to allow for all possible contingencies. The main part of the procedure, which deals with a single event, is described by the flow diagram in Figure 4.

\section{DISCUSSION}

The technique described has proved time saving and less laborious than the manual procedures employed previously. Preparation of the records for the analogue digital converter is best carried out by a doctor experienced in motility work, but the digitization can be left to a trained technician. The time spent on analysis of motility studies has been more than halved while the yield of information has greatly increased.

To test the reproducibility of the technique, two observers each analysed a set of studies in duplicate. Altogether 31 leads were analysed containing data from two subjects under a variety of conditions. The computed results for motility index, percentage duration of activity, and percentage of rapid waves were extracted from the results, and analyses of variance are shown in Table $I$. (The rapid waves analysis refers to fewer data because there were no rapid waves in several leads.) The agreement between duplicates was satisfactory, with standard deviations of $0.26 \mathrm{~cm}$ water, $1.7 \%$ and $2.1 \%$ for the three quantities. In addition, the consistent differences between observers were small, and for the percentage of activity and rapid waves they were no larger than would be expected from the differences between duplicate readings by one observer; for average intensity (motility index) the difference amounted to no more than $+0.09 \mathrm{~cm}$ of water, which may be compared with a mean figure for this variable of

TABLE I

ANALYSES OF VARIANCE OF RECORDS ANALYSED REPEATEDLY

\begin{tabular}{|c|c|c|c|c|c|c|c|}
\hline & & \multicolumn{2}{|c|}{$\begin{array}{l}\text { Average Intensity } \\
\text { (Motility Index) }\end{array}$} & \multicolumn{2}{|c|}{$\begin{array}{l}\text { Percentage Duration } \\
\text { of Activity }\end{array}$} & \multicolumn{2}{|c|}{$\begin{array}{l}\text { Percentage of } \\
\text { Rapid Waves }\end{array}$} \\
\hline & & $\begin{array}{l}\text { Degrees of } \\
\text { Freedom }\end{array}$ & $\begin{array}{l}\text { Mean } \\
\text { Square }\end{array}$ & $\begin{array}{l}\text { Degrees of } \\
\text { Freedom }\end{array}$ & $\begin{array}{l}\text { Mean } \\
\text { Square }\end{array}$ & $\begin{array}{l}\text { Degrees of } \\
\text { Freedom }\end{array}$ & $\begin{array}{l}\text { Mean } \\
\text { Square }\end{array}$ \\
\hline Differences between observers & $\begin{array}{l}\text { Consistent } \\
\text { Random }\end{array}$ & $\begin{array}{r}1 \\
30\end{array}$ & $\begin{array}{l}0.262^{1} \\
0.062\end{array}$ & $\begin{array}{l}1 \\
30\end{array}$ & $\begin{array}{l}7.60 \\
2.95\end{array}$ & $\begin{array}{r}1 \\
13\end{array}$ & $\begin{array}{l}1.41 \\
1.86\end{array}$ \\
\hline \multicolumn{2}{|c|}{ Differences between duplicates by one observer } & 62 & 0.067 & 62 & $2 \cdot 85$ & 28 & 3.59 \\
\hline \multicolumn{2}{|c|}{ Average differences between observers } & & $+0.09 \mathrm{~cm}$ & & $-0.50 \%$ & & $+0.32 \%$ \\
\hline
\end{tabular}


$4.71 \mathrm{~cm}$ of water. It should be stated, however, that these results are based on leads lasting for 10 to 30 minutes and each containing several events. In a very short lead (e.g. less than 10 minutes), relatively slight disagreement between observers, which may, for example, move an event out of the 'rapid' category, can show up as numerically large differences in the summary quantities. Such very short leads, however, are not likely to be used in practice.

The development of this method has been justified on utilitarian grounds alone, but it is not unreasonable to hope that with fuller analysis of the intraluminal pressure records data of clinical or biological importance may emerge, which it would not have been possible to acquire with the older techniques. For example, extension of the method to the study of relative timing of events in different pressure leads may be relevant to abnormalities of transport of the colonic contents.

\section{SUMMARY}

The analysis of intraluminal pressure records from the alimentary tract is laborious and unstandardized. To minimize the labour involved in analysis of the pressure tracings and to provide for easy data retrieval, a technique for computer analysis of the records has been devised. An off-line system has been adopted, where a human operator edits the records, which are then digitized in an analogue to digital converter. The computer program provides an analysis of six variables from each pressure lead. The accuracy of the method has been found to be satisfactory and a substantial saving of time required for analysis has been achieved.

We are grateful to Mr. W. J. Perkins, Department of Engineering, National Institute for Medical Research, for his encouragement and help. We thank Mr. K. Bajaj, M.R.C. Clinical Research Centre, for programming assistance.

Copies of the program can be obtained from Professor M. J. R. Healy, M.R.C. Clinical Research Centre, 171-174 Tottenham Court Road, London, W.1.

\section{REFERENCES}

Adler, H. F., Atkinson, A. J., and Ivy, A. C. (1941). A study of the motility of the human colon: an explanation of dysynergia of the colon, or of the 'unstable colon'. Amer. J. dig. Dis., 8, 197-202.

Arfwidsson, S. (1964). Pathogenesis of multiple diverticula of the sigmoid colon in diverticular disease. Acta chir. scand., suppl. 342, 12.

Atkinson, M., Edwards, D. A. W., Honour, A. J., and Rowlands, E. N. (1957). Comparison of cardiac and pyloric sphincters. Lancet, 2, 918-922.

Chapman, W. P., Rowlands, E. N., Taylor, A., and Jones, C. M. (1950). Multiple balloon-kymograph recording of variations in motility of the upper small intestine in man during long observation periods before and after placebo administration. Gastroenterology, 15, 341-355.

Chaudhary, N. A., and Truelove, S. C. (1961). Human colonic motility: a comparative study of normal subjects, patients with ulcerative colitis, and patients with the irritable colon syndrome. Ibid., 40, 1-36.

Code, C. F., Hightower, N. C., Jr., and Morlock, C. G. (1952). Motility of the alimentary canal in man: review of recent studies. Amer. J. Med., 13, 328-351.

Connell, A. M. (1961). The motility of the pelvic colon. I. Motility in normals and in patients with asymptomatic duodenal ulcer Gut, 2, 175-186.

-, Texter, E. C. Jr., and Vantrappen, G. (1965). Classification and interpretation of motility records. Amer. J. dig. Dis., 10, 481-483.

Deller, D. J., and Wangel, A. G. (1965). Intestinal motility in man. I. A study combining the use of intraluminal pressure recording and cineradiography. Gastroenterology, 48, 45-57.

Farrar, J. T. (1960). Use of a digital computer in the analysis of intestinal motility records. I.R.E. Trans. Med. Electron., ME-7, 259-263.

- Elfenbein, L., Steinherg, C. A., and Bloom, A. (1964). Wave form analysis of gastrointestinal pressure dynamics Acad. Sci., 115, 680-686.

Lind, J. F., Duthie, H. L., Schlegel, J. F., and Code, C. F. (1961). Motility of the gastric fundus. Amer. J. Physiol., 201, 197-202.

Misiewicz, J. J., Waller, S. L., and Eisner, M. (1966). Motor responses of human gastrointestinal tract to 5-hydroxytryptamine in vivo and in vitro. Gut, 7, 208-216.

- - - Fox, R. H., Goldsmith, R., and Hunt, T. J. (1968). The effect of elevated body temperature and of stress on the motility of the stomach and colon in man. Clin. Sci., 34, 149159.

Posey, E. L., Jr., Dearing, W. H., Sauer, G. W., Bargen, J. A., and Code, C. F. (1948). The recording of intestinal motility. Proc. Mayo Clin., 23, 297-304.

human intestinal motor function. Amer. J. med. Sci., 221, 10-20.

Small, M. D., Brean, J. W., and Farrar, J. T. (1955). An application of autocorrelation methods to the interpretation of intestinal motility records. J. gen. Physiol., 38, 695-707.

Spriggs, E. A., Code, C. F., Bargen, J. A., Curtiss, R. K., and Hightower, N. C., Jr. (1951). Motility of the pelvic colon and rectum of normal persons and patients with ulcerative colitis. Gastroenterology, 19, 480-491.

Vantrappen, G., Hellemans, J., and Vandenbroucke, J. (1965). A method for the analysis of intestinal motility records. Amer.J. dig. Dis., 10, 449-454. 